\title{
MEDIA-FLÂNERIE: PRECEDENTES Y POSIBILIDADES \\ DISCURSIVAS EN LAS PRÁCTICAS ARTÍSTICAS \\ CONTEMPORÁNEAS
}

\author{
Pablo Martínez-Garrido \\ pabloimaga@gmail.com
}

\section{RESUMEN}

El artículo da forma al concepto del media-flâneur y su práctica, la media-flânerie, desde la óptica de las prácticas artísticas contemporáneas y como medio de abordar la complejidad de la exploración de la sociedad contemporánea y su relación con los medios, partiendo de los remanentes esenciales del flâneur tradicional provenientes de la literatura del siglo xıx y las vanguardias artísticas del xx. Para ello, comprende el paradigma que suponen plataformas digitales como Google, cuyas herramientas y códigos de representación intervienen en la comprensión del mundo en un sentido hiperreal, y propone tres posibilidades discursivas a través de la categorización abierta de prácticas artísticas contemporáneas que emplean la media-flânerie como estrategia.

Palabras Clave: flâneur, deriva, mapa, simulación, artes visuales, Google, vigilancia, medios digitales, cultura digital.

\section{MEDIA-FLÂNERIE: PRECEDENTS AND DISCURSIVE POSSIBILITIES IN CONTEMPORARY ARTISTIC PRACTICES}

Abstract

The article gives shape to the concept of the media-flâneur and its practice, the media-flânerie, from the perspective of contemporary artistic practices and as a means of addressing the complexity of the exploration of contemporary society and its relationship with the media, starting from the essential remnants of the traditional flâneur from the literature of the 19th century and the artistic avant-gardes of the 20th. For this, it understands the paradigm that digital platforms such as Google suppose, tools and codes of representation intervene in the understanding of the world in a hyper-real sense, and it proposes three discursive possibilities through the open categorization of contemporary artistic practices that use media-flânerie as a strategy.

KEYwords: flâneur, derive, map, simulation, visual arts, Google, surveillance, digital media, digital culture. 


\section{INTRODUCCIÓN}

En la obra de Walter Benjamin existe un análisis exhaustivo de la figura del flâneur enmarcado especialmente el campo de la literatura, aunque estas consideraciones no llegaron a ver la luz hasta ańos después de su muerte. El editor Rolf Tiedemann se encargó de recopilar su pensamiento en una antología titulada El París de Baudelaire. El libro antepone a tres grandes escritores de su tiempo que abordaron la flânerie en tres contextos diferentes: Charles Baudelaire en París, Edgar Alan Poe en Londres y E.T.A. Hoffman en Berlín. Los tres puntos de vista reunidos aportan una panorámica rica sobre la Europa del siglo xIx y tres de las grandes potencias mundiales de la época. Concretamente, para Benjamin el flâneur correspondía con la figura del personaje (a menudo sospechoso) que busca refugio en las masas para analizar la sociedad desde dentro. Esa figura, que Poe definió en su poesía como el hombre en la multitud, sería interpretada por Benjamin como «alguien que no está seguro de su propia sociedad. Por eso busca la multitud; no muy lejos de aquí se encontrará la razón de por qué se esconde la gente» .

Esta formulación del flâneur, o de su práctica: la flânerie, ha tenido sus ecos a lo largo de las épocas hasta nuestros días. Las vanguardias artísticas vieron con interés las propuestas que la relacionaban con la experiencia del movimiento y de la velocidad. Es destacable la postura adoptada por los dadaístas, que explotaron el aspecto estético de la flânerie, "como forma artística que se inscribe directamente en el espacio real y en el tiempo real, sin soportes materiales» ${ }^{2}$. También fue muy practicada por los surrealistas y, especialmente, por los situacionistas de mediados de siglo, que vieron en esta experiencia la posibilidad de una aplicación política contra la sociedad del espectáculo, cuyo ideólogo sería Guy Debord, que enumeró las posibilidades discursivas de la flânerie en su texto Teoría de la deriva.

Ahora bien, la incógnita que esta investigación pretende resolver es la de cómo llevar la flânerie a la práctica en la sociedad actual. Para ello partimos de la observación previa de que el mundo de hoy, entre otras muchas cosas, está caracterizado por la digitalización y, en consecuencia, por la trascendencia de un entramado de tecnologías visuales que acercan la experiencia estética de otros lugares hasta nuestros dispositivos, y nos condena generacionalmente al sedentarismo y a la monetización de nuestro tiempo libre. Herramientas como Google Street View o incluso videojuegos como Assassins Creed $^{3}$ promueven el recorrido a través de versiones digitales del planeta.

1 Walter Benjamin, El París de Baudelaire (Buenos Aires: Eterna Cadencia, 2012), 114.

2 Francesco Careri, Walkscapes: El andar como práctica estética (Barcelona: Gustavo Gili, 2014), 75.

3 Aclaremos que la empresa que lo desarrolla, Ubisoft, emplea sus mapas y modelos tridimensionales de manera complementaria como material educativo. Su interpretación de la catedral de Notre-Dame, incluso, ha sido empleada para la reconstrucción del templo tras el incendio de 2019: Eduardo Malo, «Assasins's Creed ayudará en la reconstrucción de Notre Dame», MuyComputer, 
De modo que el nuevo flâneur no explora la ciudad expresamente deambulando entre la multitud. Más bien forma parte de una multitud de identidades digitales almacenada en tremendos centros de datos y contempla el panorama a través de las interfaces de multitud de dispositivos. Hoy la práctica de la flânerie tendría más relación con el cuento del berlinés Hoffmann La ventana esquinera de mi primo ${ }^{4}$, donde un flâneur parapléjico analiza a la multitud desde una ventana elevada, limitándose a imaginar que recorre las calles e interactúa con los transeúntes. La pantalla ofrece una posición privilegiada al espectador y cosifica lo representado. Le lleva por los centros turísticos y le ofrece información relevante de cada lugar. Tampoco visita los suburbios, las zonas industriales ni las zonas conflictivas si no es a través de un mediador que decide previamente cómo va a sentirse ese espectador. Por lo tanto, no pone en riesgo su cuerpo.

En definitiva, el mundo es ahora su propia imagen o su propio simulacro, como diría Baudrillard, que retomó el mito borgiano acerca de la relación del mundo con sus representaciones, hoy mucho más compleja:

Hoy en día, la abstracción ya no es la del mapa, la del doble, la del espejo o la del concepto. La simulación no corresponde a un territorio, a una referencia, a una sustancia, sino que es la generación por los modelos de algo real sin origen ni realidad: lo hiperreal. El territorio ya no precede al mapa ni le sobrevive. En adelante será el mapa el que preceda al territorio y el que lo engendres.

De este modo, la práctica actual de la flânerie no puede ajustarse expresamente al propio territorio, sino a los medios que le dan forma. Merece así una nueva definición: la media-flânerie. Y es el media-flâneur su sujeto, quien, por otra parte, reinterpreta las estrategias de los siglos pasados para tratar de comprender la sociedad que ha traído consigo la revolución digital.

\section{METODOLOGÍA}

La redacción de este artículo se ha desarrollado a partir de la investigación y relación entre referencias bibliográficas de distintos campos como la sociología, la filosofía crítica cultural; pero está promovida principalmente por el análisis de numerosas prácticas artísticas. En este sentido, se ha prestado atención a que las prácticas aquí reseñadas no se relacionen con las referencias teóricas como meras

https://www.muycomputer.com/2019/04/17/assasins-creed-reconstruccion-notre-dame/ (consultado el 30-8-2021).

${ }^{4}$ E.T.A. Hoffmann, «La ventana esquinera de mi primo», El espejo gótico, http://elespejogotico.blogspot.com/2009/11/la-ventana-esquinera-eta-hoffmann.html (consultado el $31 \mathrm{de}$ agosto de 2021)

${ }^{5}$ Jean Baudrillard, Cultura y simulacro (Barcelona: Kairós, 1978), 6. 
ilustraciones de las mismas, sino que sea el arte el campo por el que sea dirigida la argumentación, reconociendo a cada proyecto su potencial ensayístico.

A su vez, este artículo forma parte del desarrollo de mi investigación de tesis doctoral, para la cual estoy completando un directorio online $e^{6}$ que recopila numerosos referentes artísticos en torno al concepto de media-flânerie de las últimas dos décadas. Todos los referentes artísticos de este texto han sido recogidos previamente en este directorio, el cual está disponible para consulta de toda la comunidad artística, académica y estudiantil con fines referenciales y educativos y se va actualizando a medida que avanza la investigación.

\section{DESARROLLO}

\section{EL MEDIA-FLÂNEUR EN LOS DISCURSOS ARTÍSTICOS Y ACADÉMICOS CONTEMPORÁ- NEOS}

Dentro de las prácticas artísticas actuales, ¿¿de qué manera toma forma el concepto de media-flâneur? Desde esta investigación, la primera conclusión es que la definición de esta figura tiene, principalmente, una estrecha relación con aquellas prácticas que se caracterizan por el empleo de las herramientas ya existentes en la red, provenientes en mayor medida de la corporación Google, y que aquí puede entenderse como todo un paradigma. La pregnancia de Google en cuanto a herramientas como Google Maps, Street View, Youtube o Art Project ofrece a los artistas todo un laboratorio con el que experimentar y su manejo les ofrece muchos planteamientos discursivos.

En 2012 el artista Emilio Vavarella desarrolló el triple proyecto The Google Trilogy como manera de explorar las relaciones entre humanos, poder y errores tecnológicos (fig. 1). Vavarella representó los resultados de largas sesiones de navegación a través de Street View para dar forma a tres narrativas diferentes donde la protagonista no es otra que la cámara esférica que fotografía el mundo desde los vehículos de Google. Para ello, centró la atención en los glitches técnicos producidos por esta, así como en eventos capturados accidentalmente y los autorretratos furtivos de los propios conductores de Street View. En el texto que acompaña al proyecto, Vavarella hace referencia al flâneur como el verdadero conocedor de las metrópolis modernas y reconoce la potencialidad de las nuevas tecnologías digitales para visibilizar de qué manera los medios dan forma al mundo hoy en día. Es en este panorama donde el artista se aventura a plantear la práctica de la media-flânerie:

A medida que las ciudades modernas cambian radicalmente y se vuelven cada vez más interconectadas, el concepto de medios de comunicación puede reflejar la

6 Pablo Martínez Garrido, «Proyectos artísticos», Non Player Character. https://nonplayercharacter.home.blog/category/proyectos-artisticos/ (consultado el 31 de agosto de 2021). 


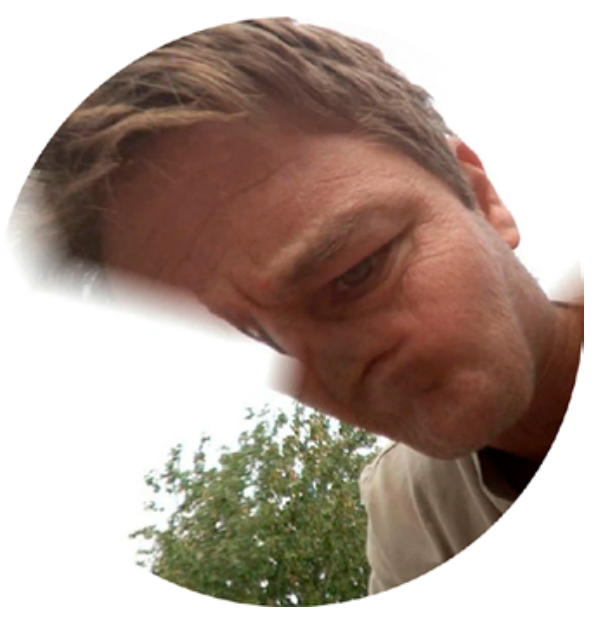

Fig. 1. The Driver and the Cameras, Emilio Vavarella.

Uno de los proyectos de The Google Trilogy.

especificidad de un entorno saturado de medios. Por ejemplo, mientras que flânerie existía en relación con el movimiento a través de la arquitectura específica de las salas de juego de París, la media-flânerie es, en cambio, el producto de nuevos movimientos digitales a través de arquitecturas de software, autopistas de información, agregados de datos e interfaces híbridas?.

Otro aporte interesante es el proyecto Metrópolis ${ }^{8}$ (2019), del fotógrafo Jon Gorospe: una intensa recopilación de capturas recogidas de la plataforma Street View da fe de un viaje alrededor del mundo que el fotógrafo ha realizado desde su ordenador. Las fotografías registran decenas de situaciones curiosas donde sus protagonistas comparten el extrañamiento por la misma cámara-vehículo que recorre sus ciudades, pueblos y carreteras. Aquí la flânerie se muestra en su carácter más esencial. No es un espacio físico lo que se recorre, y por lo tanto este espacio no es comprendido por el cuerpo del flâneur. Aquí la flânerie se expresa mediante la mirada en semejanza con la labor del fotógrafo, que recorre una especie de gran fotografía hipertextual e interactiva. El proyecto promueve un nuevo replanteamiento de la figura del $f \hat{a}-$ neur como una mirada activa en un mar de imágenes, donde cada día se producen innumerables registros de los mismos monumentos y lugares. Tal como describe

7 Emilio Vavarella, «Some personal thoughts on Google mapping». Web personal. https:// emiliovavarella.com/archive/google-trilogy/report-a-problem/ (consultado el 31 de agosto de 2021).

${ }^{8}$ Rubén Ángel Arias, «Metrópolis. Jon Gorospe», Centro Cultural Montehermoso, https:// montehermoso.net/pagina.php?id_p=2293 (consultado el 31 de agosto de 2021). 


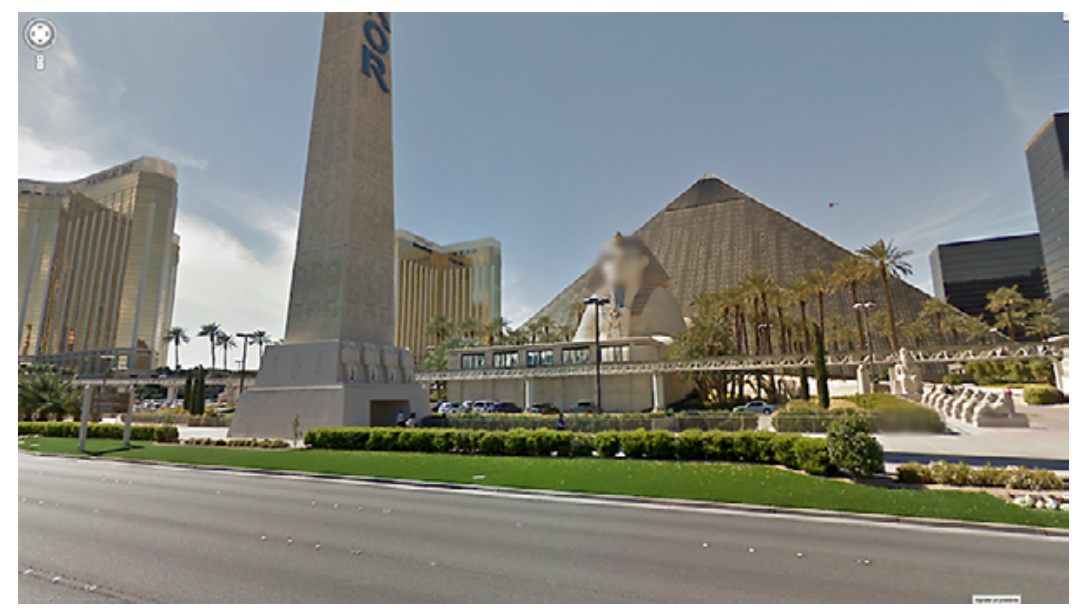

Fig. 2. Anonymous Gods, Marion Balac.

Rubén Ángel Arias en texto del proyecto: «El fotógrafo es ahora, más que nunca, un antólogo, un flâneur sumergido en una imponente masa de imágenes a la deriva»?

Por otro lado, son especialmente sugerentes aquellas prácticas en las que la hiperrealidad interfiere en la experiencia estética y discursiva del mundo. Por nombrar algunos ejemplos, y aunque los artistas no plantean expresamente la práctica de la media-flânerie, en esta línea existen proyectos como Anonymous Gods ${ }^{10}$ (fig. 2), de Marion Balac, que reúne mediante capturas una serie de monumentos sobre los cuales ha intervenido el algoritmo con el que Street View difumina los rostros de los peatones. Aquí figuras monumentales de carácter religioso o alegórico son entendidas por el algoritmo como humanas, prueba del acto profanador ejercido por una inteligencia artificial.

También destacaría en este sentido The non-imaginary museum ${ }^{11}$, que lleva siendo desarrollado por Mario Santamaría desde 2013. Aquí el artista emplea la herramienta Art Project, que Google lanzó con el objetivo de acercar el arte de los museos a la gente. No obstante, Santamaría centra su interés en los límites de este discurso. El proyecto reúne capturas de los difuminados sobre obras concretas que el algoritmo censura y que llaman la atención sobre las paredes de los museos, visibilizando los límites de la representación, a menudo legales, que interfieren en la exploración de estos espacios virtuales.

9 Ibidem.

${ }_{10}$ Marion Balac, «Anonymous Gods», web personal, http://www.marionbalac.com/works/ anonymous-gods/ (consultado el 31 de agosto de 2021).

${ }^{11}$ Mario Santamaría, «The non-imaginary museum», Righted-museum, https://rightedmuseum.tumblr.com/ (consultado el 31 de agosto de 2021). 
Por otra parte, no son muy numerosos los referentes existentes que hayan abordado directamente la media-flânerie desde un punto de vista académico. Aunque merece una mención especial el artículo redactado por el estadounidense Todd Presner, el cual «explora las complejas formas en las que los espacios de la ciudad, particularmente Berlín, han sido remediadas en el mundo contemporáneo de las tecnologías mediáticas geoespaciales como Google Earth»" ${ }^{12}$. Aquí abarca, en particular, la exploración de los mapas virtuales como práctica de media-flânerie, y defiende expresamente la similitud de la exploración por ordenador con el flâneur de Hoffman, de la misma manera que hacemos en este artículo, donde «la flânerie ha sido desasociada del caminar entre la multitud y elevada hacia un nivel sublime de movilidad aparentemente sin restricciones ni fricciones ${ }^{13}$.

\section{LOS MEDIOS COMO TERRITORIO}

El media-flâneur tiene aún muchos horizontes que explorar. Si bien es cierto que Google, por su importante vigencia, se ha convertido en paradigma y el empleo de sus herramientas se ha hecho común debido a la disponibilidad para creadores de contenido, en esa definición de media caben muchas más tecnologías. Es necesario reconocer que el territorio a explorar son esos mismos medios, y es fundamental conocer cómo se edifican, relacionan y dan forma a nuestro mundo si queremos mirar tras los bastidores para descubrir la infraestructura que da forma a esa hiperrealidad.

En un análisis exhaustivo, Lev Manovich proponía un desglose de lo que él denominaba tecnologías mediáticas, divididas en tecnologías de representación (como las películas, los sistemas de reproducción de vídeo y audio o de almacenamiento digital); y en tecnologías de comunicación, que sintetiza como todo aquello que contenga el prefijo tele-, como el teléfono, la televisión o la telepresencia ${ }^{14}$. Para este autor la fusión de ambas tecnologías promueve la creación de otras técnicas y paradigmas, como las de la realidad virtual o la vigilancia masiva. Y como consecuencia, la intervención de todos estos medios (entre los cuales da un valor especial al cine) genera un distanciamiento entre el objeto y el espectador. Este hecho afecta directamente a la manera de asimilar el planeta, propiciando una "progresiva pérdida de realidad que sufre el horizonte terrestre [...] que tiene como resultado el inmininente predominio de la perspectiva en tiempo real de la óptica ondulatoria por encima del espacio real de la óptica geométrica lineal del Cuatrocientos» ${ }^{15}$.

12 Todd Presner, «Digital Geographies: Berlin in the Ages of New Media». Spatial Turns 75 (2010): 447-469 en Brill: https://doi.org/10.1163/9789042030022_023 (consultado el 31 de agosto de 2021).

13 Ibidem.

${ }^{14}$ Lev Manovich, El lenguaje de los nuevos medios de comunicación: La imagen en la era digital (Barcelona: Paidós, 2006), 221-222.

${ }_{15}$ Paul Virilio, «Big Optics», On Justifying the Hypothetical Nature of Art and the Non-Identicality within the Object World, Peter Weibel (Archive of Digital Art (ADA), 1992), 90. 


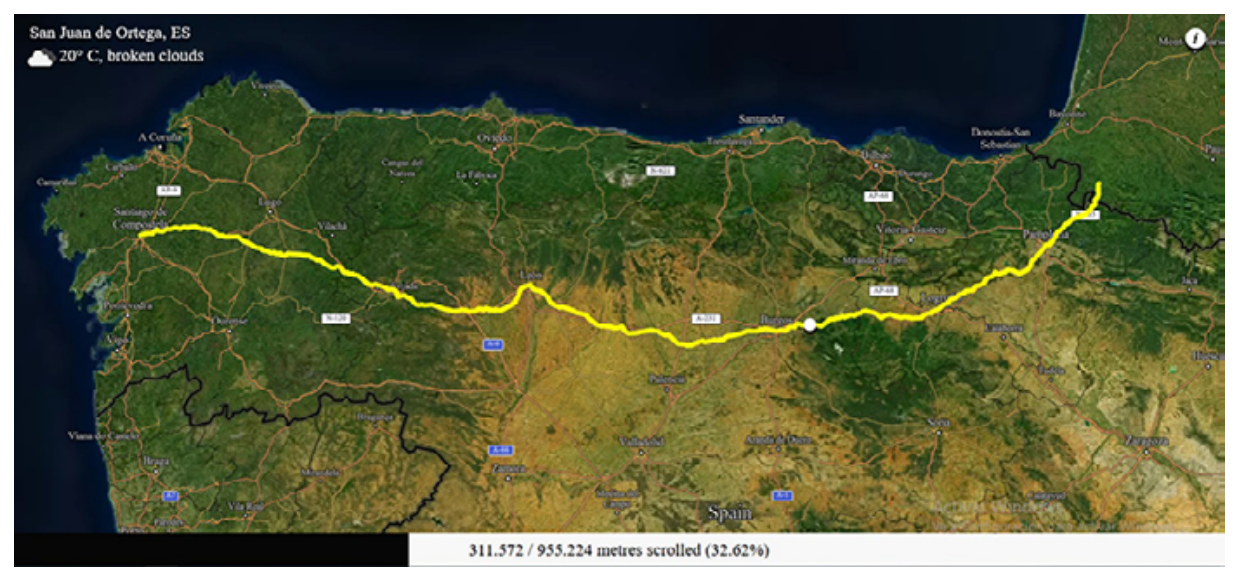

Fig. 3. Digital Detox, Marco Land.

En alusión a este fenómeno descrito por Virilio, nos viene a la mente el proyecto Digital Detox (fig. 3), iniciado por Marco Land en 2019 y que todavía se está llevando a cabo. Una extensión de Google Chrome construida por el artista que registra a tiempo real la distancia total recorrida al hacer scroll en su ordenador: cada vez que Land recorre una página web, la extensión mide ese movimiento. Luego esa distancia se traslada a un recorrido, generado por Google Maps y alojado en una página web ${ }^{16}$, moviendo un marcador a lo largo de este. El trayecto en cuestión es el Camino Francés, una de las principales rutas hasta Santiago de Compostela.

Aquí el artista en realidad no está caminando, sino que es consciente de su propio movimiento a través de la web, que no es más que una ilusión provocada por la interfaz. Como en la cinta de correr del gimnasio, la noción de distancia nos es dada por el monitor de la máquina. El recorrido, por tanto, se vuelve estático y pierde el factor de la distancia, de modo que la experiencia recaería en la sensación temporal: recorremos tanto espacio teórico como tiempo y velocidad empleamos. De este modo, la acción de Marco Land, que dentro de nuestro análisis encaja perfectamente en la definición de media-flânerie, ilustra cómo la intervención de los medios conlleva pérdida con la realidad que anunció Virilio. La distancia pierde valor para la experiencia y se capitaliza como información, perdiendo toda objetividad. No obstante, en el caso de Digital Detox, esos datos adquieren un sentido más profundo cuando se introducen en el contexto del Camino de Santiago, que, aunque el artista no lo está realizando, sí los relaciona a una larga tradición cultural y religiosa y los dota de una profunda relevancia.

16 Marco Land, «Digital Detox», Web del proyecto, https://digitaldetox.marco.land/ (consultado el 31 de agosto de 2021). 
Pero antes de seguir deberíamos tomarnos un tiempo para pensar qué forma tiene este mundo del que estamos hablando. Volviendo a lo que hemos dicho antes, la catalogación de los medios antes propuesta por Manovich se ha venido haciendo más compleja a lo largo de la pasada década con la llegada de tecnologías como la web 2.0 o el asentamiento de plataformas como Google, Youtube, Netflix, etc. En un análisis más reciente, Geert Lovink señala un nuevo estatus de los medios basado en una interrelación compleja en forma de plataformas, superficies basadas en la combinación de medios cuyo fin es permitir la interacción en diferentes flancos:

Las plataformas ahora son vistas como la arquitectura a imitar. [...] la plataforma, tal como la conocemos hasta ahora, no es solo un sitio web de éxito. Tener una fuerte presencia en las redes sociales es una cosa; construir una plataforma es algo de un orden completamente diferente. [...] las plataformas se crean solo a través de una masa crítica de usuarios y datos ya existente. Esto requiere un complejo conjunto de redes de subnivel que sustentan la plataforma. Y estas redes, a su vez, dependen de un conjunto interoperable de estándares técnicos y protocolos que ya deben estar en su lugar ${ }^{17}$.

Además, este autor hace referencia a una dimensión superior: una combinación de plataformas a escala planetaria como la que propone Benjamin Bratton en su ensayo The Stack, texto al que Lovink reconoce como «el sucesor de The Language of New Media de Lev Manovich ${ }^{18}$. The Stack o la pila propone un nuevo estatus para la nube, independiente, llegando a convertirse «en un cuarto estado junto a la tierra, el aire y el mar ${ }^{19}$. Tal y como lo definiría Bratton, la pila, como un conjunto de plataformas, atraviesa dimensiones, fronteras y mercados. Un sistema no dependiente de un único poder que trasciende las arquitecturas robándoles espacio y volviendose cada vez más hegemónico:

Las redes hacen espacio y toman espacio, y como cualquier otra arquitectura, por sus inscripciones en una ubicación determinada, excluyen otras posibilidades de estar allí. Sin embargo, las redes viven de manera diferente a los edificios, y superan lo que un homínido bípedo reconocería como una sola ubicación, pero sin embargo son placenteras. Los bordes y las líneas de las redes producen interiores y exteriores, por lo que las redes no solo se superponen en un territorio dado, sino que también producen un territorio real al rallarlo ${ }^{20}$.

En el sentido de cómo estas redes promueven su propio territorio, es muy ilustrativo el mapamundi realizado por el analista de datos Paul Butler en 2011

${ }^{17}$ Geert Lovink, Tristes por diseño. Las redes sociales como ideología (Bilbao: Consonni, 2019), 122.

18 Ibidem, 125.

${ }_{19}$ Benjamin Bratton, The Stack: On software and sovereignty (Cambridge (MA): MIT Press, 2015), 5.

${ }^{20}$ Ibidem, 29. 


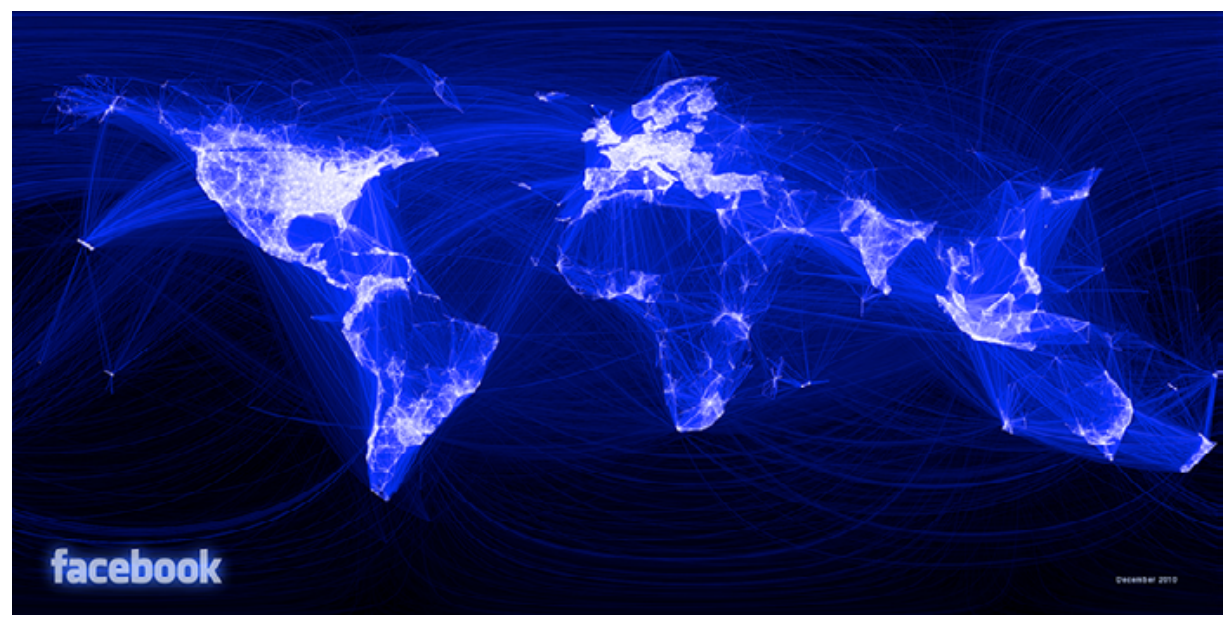

Fig. 4. Facebook Friendship World Map, Paul Butler.

(fig. 4), quien por aquella época trabajaba para Facebook, y que desarrolló a través de la interconexión entre amistades a partir de los datos de la red social. Este mapa ilustra muy bien el área de influencia de la infraestructura de Facebook por aquel entonces y los límites de su capacidad de recoger datos y, por lo tanto, la manera en que su inteligencia artificial es capaz de comprender el mundo. En definitiva, el mapamundi se caracteriza por la limitación a los territorios dominados por Occidente, excluyendo áreas subdesarrolladas y, por supuesto, las infraestructuras de los bloques chino y ruso, que por su parte gozan de un entramado tecnológico capaz de competir con el occidental. Cabe señalar que en la actualidad Facebook forma parte del entramado mucho mayor de Google, pero desgraciadamente Butler no ha llegado a elaborar un nuevo mapa incluyendo los nuevos datos.

La pila es, en definitiva, el resultado de una relación entre plataformas las cuales a su vez son resultado de la relación entre diferentes medios y poderes. Sin embargo, aunque su influencia puede ser muy grande, es prudente comprender sus límites de influencia y representabilidad, pues su display está sometido a factores geopolíticos. No en vano, para Bratton este entorno tecnológico es utilizado como arma, preferentemente por parte de las potencias anglosajonas, con el fin de «descualificiar a sus enemigos militares para vigilar sus propias incapacidades morales y técnicas mediante arquitecturas «universales" que de hecho son extensiones de sus propios intereses específicos» ${ }^{21}$.

Encarrilando de nuevo nuestro tema, otra puesta en práctica de mediaflânerie toma conciencia de las posibilidades y limitaciones de esta infraestructura

21 Benjamin Bratton, op. cit., 31. 
planetaria. El proyecto Geocinema, que desarrollan Asia Bazdyrieva, Solveig Suess y Jessika Khazrik, hace uso "de las redes sensoriales a escala planetaria -teléfonos móviles, cámaras de vigilancia, satélites, geosensores- como un aparato cinematográfico ampliamente distribuido: una cámara $»^{22}$. Por tanto, cabe señalar que lo consideramos como un proyecto de media-flanerie por el hecho de que toma las herramientas e infraestructura que existen en el medio que explora, aun sin poseerlas, para dotarlas de un sentido artístico o crítico. Geocinema consiste en una serie de episodios que abordan la manera en la que conocemos nuestro planeta a través de los medios. Tal como explican en su página web:

Al detectar fragmentos de la Tierra, sus operaciones generan terabytes de datos brutos, arquitecturas de infraestructura, trabajo oculto, clima disonante, políticas gubernamentales, gestión científica, entornos y situaciones, cada uno de los cuales participa en el cambio de la estructura de la Tierra a través de sus propios conjuntos de escalas y temporalidades. Aquí, la representación de la Tierra es la suma de un proceso de edición descentralizado con su imagen, que es cualquier cosa menos completa ${ }^{23}$.

En resumen, el análisis de este entorno puede ser beneficioso a la hora de conocer los límites de representabilidad de Occidente y encontrar numerosas brechas dentro del discurso computacional, el cual fuerza a hacernos creer en los sistemas de administración de datos prácticamente como leyes naturales, más cerca de un sistema de creencias que de la realidad. No hay más que remitirse a las palabras de Remedios Zafra:

Los canales de circulación hegemónicos no son fruto de un carácter colectivo y público, negociado desde voluntades que son dueñas de sí y de sus espacios comunes, sino que, con aspecto de espacio público, son canales privativos dominados por el capital y por unos pocos que atraviesan las vidas y las elecciones de los conectados ${ }^{24}$.

\section{MANERAS DE ABORDAR LA MEDIA-FLÂNERIE}

Para el media-flâneur aquella pila de Bratton supone una analogía de la revolución digital con respecto a las metrópolis de la revolución industrial. Este territorio es un entorno complejo y está atravesado por lógicas y medios innumerables que a su vez intervienen en la comprensión misma del espacio. Recorrer este espacio, como el interior de un ordenador de escala planetaria, genera ciertos planteamientos a explorar desde un punto de vista artístico. Desde esta investigación se plantea una categorización abierta de diferentes prácticas artísticas entendidas como prácticas

${ }^{22}$ Asia Bazdyrieva et al., «Geocinema», Geocinema, https:/geocinema.network/ (consultado el 31 de agosto de 2021).

${ }^{23}$ Ibidem.

${ }^{24}$ Remedios Zafra, Ojos y capital (Bilbao: Consonni, 2015), 133. 
de media-flânerie, en función a los aspectos que abordan dentro de un entramado telúrico-mediático. Por el momento, se proponen tres enfoques a partir de diferentes prácticas artísticas. En primer lugar, la pregunta acerca de cómo las ciudades han sido transformadas por los medios. Por otro lado, la huida o señalamiento del entramado de vigilancia masiva que se sostiene entre los sistemas de seguridad policial y militar y los medios que dan forma al Big Data. Y, por último, la exploración de aquellos territorios alejados de las ópticas. No obstante, la siguiente categorización no presta atención al hecho de que los proyectos artísticos tienen distintas formas de comprenderse, por lo que más bien tiene la intención de animar a otros investigadores y creadores a abrir nuevos caminos. Valga lo que viene a continuación, por tanto, como un germen de las posibilidades discursivas que ofrece la media-flânerie.

\subsection{LA CIUDAD MEDIA}

Las ciudades, hoy mediatizadas, han sido transformadas radicalmente a causa de sus propias representaciones. La enorme producción de imágenes de los monumentos, lejos de marcar una diferenciación con respecto a otros lugares, sitúa a todas las ciudades en la homogeneidad representativa a la que le condena el turismo como estrategia de mercado. Todas las ciudades son atractivas, todas tienen unos espacios clave que se deben visitar. Tanto da si es la torre Eiffel o el palacio de la Alhambra. En la sobrerrepresentación de cada espacio el contexto termina perdiéndose en un mar de incertidumbres mientras prevalece la cosificación de lo representado como pura imagen de sí mismo. De este modo, los monumentos más famosos terminan convirtiéndose en simple imaginario neoliberal, en cuanto accesible exclusivamente por medio del consumo.

Esta pérdida de contexto propicia colisiones entre lo real y su propia representación. Llegando incluso al extremo de producir universos fantasiosos que pueden robar el espacio a otras realidades. En el documental Les enfants de Val d'Europe $e^{25}$, de Marion Balac, artista ya citada anteriormente, se refleja el paradigma en el que habitan los residentes del pueblo francés, construido para dar residencia a los trabajadores del parque temático Disneyland París. La historia se centra en los hijos de esos trabajadores, que han vivido toda su vida inmersos en esa simulación del universo Disney, habitando en ambos lados de la difusa frontera entre ficción y realidad. Una complejidad que fue en su momento abordada por Jean Baudrillard (1978):

Disneylandia es presentada como imaginaria con la finalidad de hacer creer que el resto es real, mientras que cuanto la rodea, Los Ángeles, América entera, no es ya real, sino perteneciente al orden de lo hiperreal y de la simulación. No se trata de

25 Marion Balac, «Les Enfants de Val d'Europe», Web personal, http://www.marionbalac. com/works/les-enfants-de-val-deurope/ (consultado el 31 de agosto de 2021). 


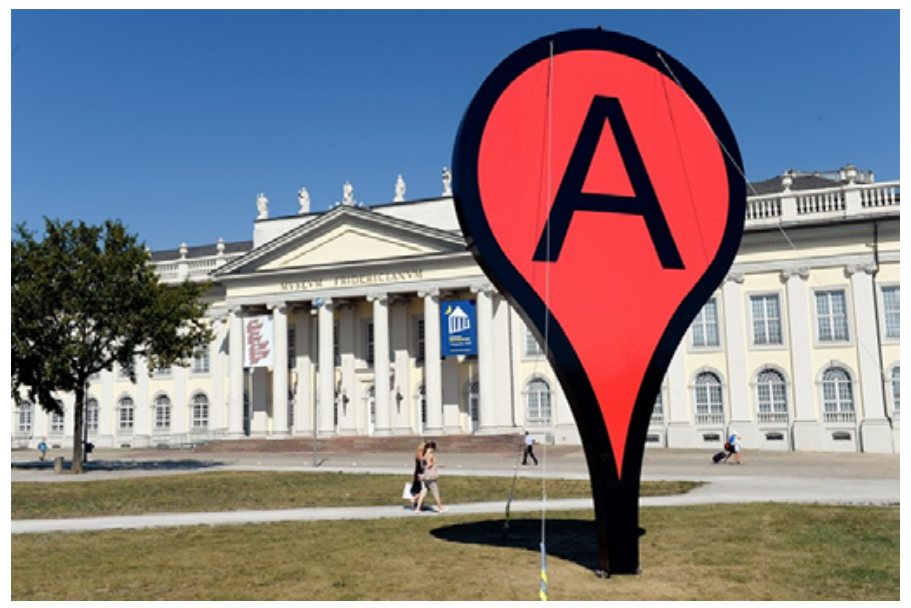

Fig. 5. Map, Adam Bartholl.

una interpretación falsa de la realidad (o ideología), sino de ocultar que la realidad ya no es la realidad y, por tanto, de salvar el principio de realidad ${ }^{26}$.

En otras palabras: para el media-flâneur los parques temáticos son, por lo general, territorios especialmente interesantes. La evidente artificialidad mediante la que están constituidos estos lugares, al igual que sucede con la realidad virtual, promueve una dualidad de interpretaciones: Disneylandia (o un festival de música, o el entorno virtual de mi visor VR) no es el mundo real; por lo tanto, lo que hay fuera sí lo es. Darse cuenta de esta trampa es esencial para romper con la dicotomía de lo real y lo imaginario. Una vez que hemos explorado estos entornos de ficción radical de una manera consciente, seremos capaces de encontrar las similitudes, intersecciones y sombras de ambas nociones en nuestro día a día. O dicho de otra manera: descubriremos que el acceso a la mayoría de estos entornos implica consumir y ser consumido, dejarse llevar por el remolino de la sociedad del espectáculo. De modo que lo necesario para nuestra liberación es, si aplicamos las viejas nociones del situacionismo, encontrar lo imaginario también en nuestra cotidianidad y utilizarlo como medio de escape de esa corriente.

Un ejemplo de provocación de estas situaciones son los trabajos de Aran Bartholl, donde la mayoría de las veces introduce fragmentos de estas representaciones virtuales en el mismo espacio físico. El proyecto $\operatorname{Map}^{27}$ (fig. 5) se centra en la ubicación de varios monumentos alrededor del mundo con forma de marcadores

26 Baudrillard, op. cit., 26.

27 Aram Bartholl, «Map», Web personal, https://arambartholl.com/map/ (consultado el 31 de agosto de 2021). 


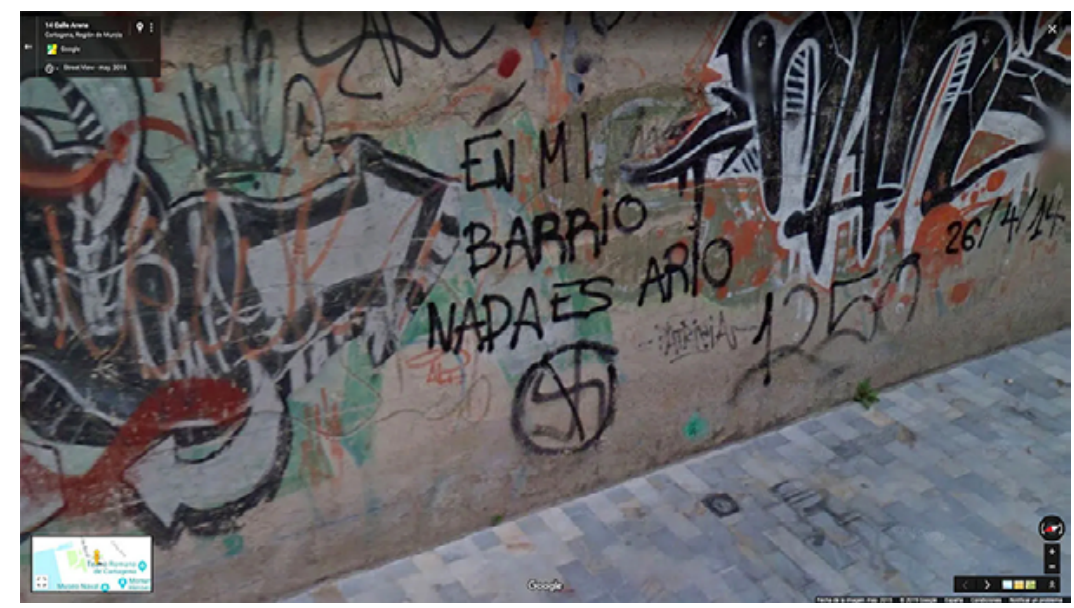

Fig. 6. Paisajes digitales de una guerra, Azahara Cerezo.

de ubicación de Google Earth. El lugar donde se erigen no es aleatorio, sino que se sitúan exactamente sobre la ubicación que Google sugiere como centro de la ciudad. Un ejemplo es el marcador que fue colocado en Kassel, Alemania, en la plaza frente al Museum Fridericianum.

Por otro lado, las ciudades en sí mismas no son lo único que sugiere la injerencia de los medios en la realidad. Realmente, las ciudades no son sino el resultado de la interacción entre distintas culturas, discursos y clases sociales que se disputan el territorio. La exploración de estas relaciones fue una de las principales características de la flânerie tradicional, y por lo tanto sigue siendo interesante para el media-flâneur.

Hoy en día existen artistas que abogan por la visualización de estos cruces. Con su narrativa experimental y estética hiperrealista, María Alcaide desarrolló My terrorist lover: un vídeo que «explora ciertas tensiones culturales de la actualidad como islamofobia o la tendencia a la radicalización y estetización de la identidad territorial utilizando un lenguaje procedente del mundo digital y youtuber ${ }^{28}$. Unas tensiones culturales que se producen en las capas de significado del territorio y que también demuestra Azahara Cerezo en Paisajes digitales de una guerra (fig. 6) ${ }^{29}$, donde reúne una serie de capturas de Google Street View que muestran pintadas y mensajes políticos visibles en muros. La artista escoge lugares con una fuerte carga histórica en relación con la guerra civil española (Ciudad Universitaria, el puerto de Cartagena y el casco viejo de Pamplona), donde se muestran pintadas antifascistas

${ }^{28}$ Maria Alcaide, «My terrorist lover», Web personal, https://mariaalcaide.com/work/myterrorist-lover (consultado el 31 de agosto de 2021).

${ }^{29}$ Azahara Cerezo, «Paisajes digitales de una guerra», Web personal, http://www.azaharacerezo.com/paisajes.html (consultado el 31 de agosto de 2021). 
y fascistas que van reescribiéndose, tachándose o borrándose a medida que pasa el tiempo. Con ello muestra cómo a través de la óptica de Google la historia se mantiene viva en ciertos lugares.

\subsection{El FLÂNEUR INVISIBLE AL APARATO DE VIGILANCIA}

Ya desde sus primeras formulaciones, el flâneur ha estado estrechamente relacionado con el desarrollo técnico del control policial. Para Edgar Alan Poe, el hombre en la multitud representaba a cualquier sujeto que actuaba camuflado en las masas. En cierta analogía con el anarquista de finales del siglo XIx y principios del xx, el $f \hat{a}$ neur habita los callejones y las galerías, observa los horarios y las pautas, y sólo aparece cuando es necesario actuar para luego volver a desaparecer. Sin embargo, debe entenderse que el hombre en la multitud también representaría otros estilos de vida, como el de las personas homosexuales, transexuales, disidentes, bohemios..., que encuentran en las ciudades el refugio social que anhelaban en sus pueblos de origen.

De la misma manera, en el contexto de Internet la situación no se muestra muy diferente; de hecho, la sofisticación de las tecnologías de rastreo que forman parte inherente de los nuevos medios ha dado como respuesta natural la diversificación y desarrollo de nuevas formas de resistencia. Ante la necesidad hackers, activistas, artistas, periodistas, criminales e incluso ciudadanos de a pie deben adquirir nuevos conocimientos técnicos como el cifrado de comunicaciones para garantizar el anonimato (que en casos extremos supone salvar la vida) o traspasar la censura a contenido prohibido en sus países mediante el uso de VPN.

El contexto de la vigilancia ha sido abordado a día de hoy por innumerables creadores y es difícil reunir una antología de estas prácticas. Sí podría señalarse un hito donde la preocupación por la vigilancia masiva se hizo visible en la cultura. Sería durante la década de los ochenta, época en la que se instalaron las primeras cámaras CCTV callejeras, y obtendría su punto álgido a comienzos de los 2000, como consecuencia de la respuesta de los gobiernos occidentales a los atentados del 11 de septiembre. De esta época son destacables las labores de concienciación por parte de algunos colectivos neoyorkinos, como las del colectivo Surveillance Camera Players (fig. 7$)^{30}$, quienes experimentaron con las posibilidades discursivas de las imágenes de vigilancia con acciones como la representación de varias obras teatrales frente a las cámaras callejeras de Nueva York. También en esta ciudad se desarrollarían otros proyectos, muchos de ellos orientados al activismo y con el fin de burlar la vigilancia y encontrar espacios de libertad, muy en la línea del concepto de zonas temporalmente autónomas desarrollado por Hakin Bey ${ }^{31} \mathrm{y}$ del pensamiento antiglobalización presente en contracumbres como las de Seattle o Génova, que propi-

\footnotetext{
${ }^{30}$ Surveillance Camera Players, Web del colectivo, http://www.notbored.org/the-scp.html (consultado el 31 de agosto de 2021)

${ }^{31}$ Hakim Bey, T.A.Z. Zona Temporalmente Autónoma (Madrid: Enclave de Libros, 1991).
} 


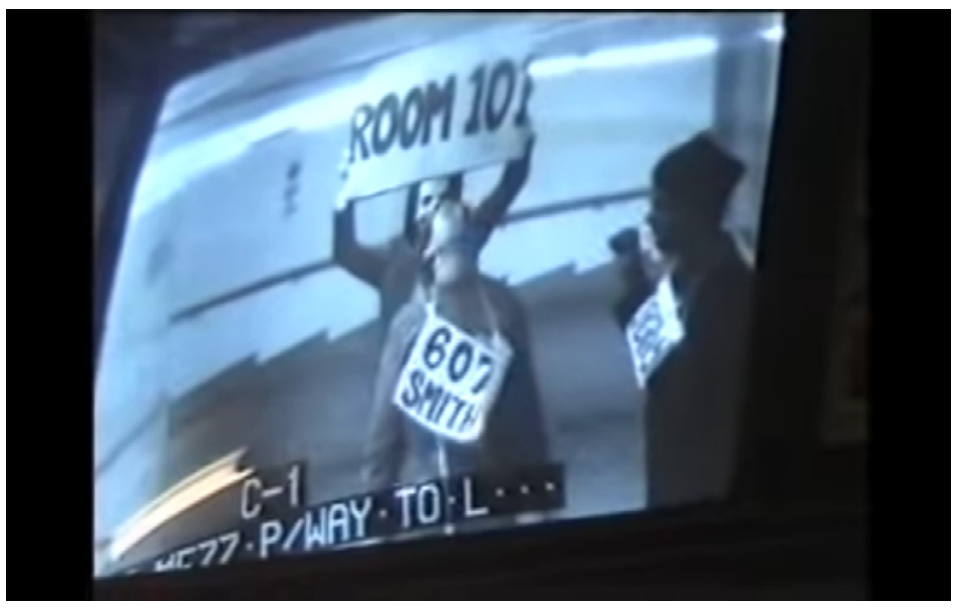

Fig. 7. Acción de Surveillance Camera Players en el metro de Nueva York.

ciaron estrategias como las descritas en el Manual de guerrilla de la comunicación ${ }^{32}$. Uno de estos proyectos es $i S e e^{33}$, del Institute of Applied Autonomy, un programa informático de navegación GPS que genera alternativas de trayectos con la menor exposición posible a las cámaras de vigilancia de Manhattan.

Dos décadas después la infraestructura de vigilancia se ha ido complejizando, así como sus tecnologías. Y aunque muchos proyectos relativamente recientes siguen experimentando con la exposición a las cámaras de vigilancia, la mayoría incluyen la problemática del software de reconocimiento biométrico, ya que otorga una nueva dimensión. Con la medición biométrica, ya sea facial o corporal, la vigilancia pasa de controlar el territorio a controlar los cuerpos también como espacio de conflicto. Así lo señalan los investigadores Lidia García y Pedro Cruz:

Ya no importa tanto el control sobre la tierra cuanto el control sobre los cuerpos. Pese a que los nuevos fascismos han traído al escenario político un re-endurecimiento de las líneas de exclusión de cada territorio, en realidad las fronteras que más importan ahora son las que se desplazan globalmente con cada cuerpo: las fronteras biométricas. Un cuerpo medido es un cuerpo que vive dentro de los límites de representación de la seguridad ${ }^{34}$.

${ }^{32}$ Luther Blisset et al., Manual de guerrilla de la comunicación (Barcelona: Virus, 2006).

33 The Institute for Applied Autonomy, «iSee», Vimeo, https://vimeo.com/6163268 (consultado el 31 de agosto de 2021).

34 Pedro Cruz y Lidia García, «Cuerpo, máscara y biopolítica. Estrategias de opacidad en la era del big data». ASRI. Arte y Sociedad 17 (2019): 25-37, https://www.eumed.net/rev/asri/17/ panoptico-digital.html (consultado el 31 de agosto de 2021). 


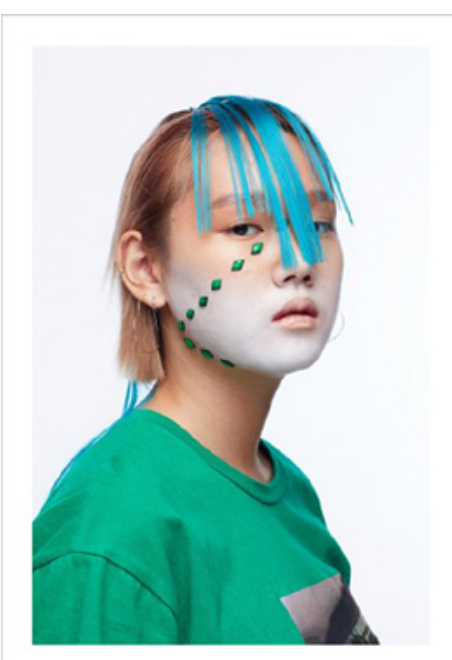

Fig. 8. CVDazzle, Adam Harvey.

Es especialmente ilustrativo el trabajo de Manu Arregui en sus Ejercicios de medición sobre el movimiento amanerado (2014-2017) ${ }^{35}$, donde los gestos atribuidos culturalmente a la homosexualidad por parte de la lógica patriarcal son analizados a través del tracking de datos de posicionamiento. Aquí, las herramientas de vigilancia son empleadas para juzgar la homosexualidad, un delito grave en numerosos países. «Al igual que con el caballo de Muybridge, el movimiento es extendido en el tiempo para tratar de encontrar aquello que la mirada heteropatriarcal es incapaz de percibir, y que trata de encontrar desesperadamente ${ }^{36}$.

No es extraño que en la misma línea discursiva muchos artistas continúen buscando estrategias de ocultación en base a sistemas de reconocimiento facial, todas ellas válidas para ser aplicadas en una sesión de media-flânerie: como en el caso del maquillaje basado en el camuflaje disruptivo de Adam Harvey en CV Dazzle (fig. 8) ${ }^{37}$, o en el de las Data-Masks ${ }^{38}$ de Sterling Crispin y el proyecto Facial Wea-

35 Manu Arregui, «Ejercicios de medición sobre el movimiento amanerado del cuerpo», web personal, https://manuarregui.com/portfolio/ejercicios-de-medicion-sobre-el-movimiento-amanerado-del-cuerpo-2017/ (consultado el 31 de agosto de 2021).

${ }^{36}$ P. Martínez Garrido, «Dudar del algoritmo», en Inmersiones 12 (Vitoria-Gasteiz: Asociación Cultural Inmersiones, 2019), 8.

37 Adam Harvey, «CVDazzle», web del proyecto, https://cvdazzle.com/ (consultado el 31 de agosto de 2021).

38 Sterling Crispin, «Data masks», web personal, http://sterlingcrispin.com/data-masks. html (consultado el 31 de agosto de 2021). 
ponization Suite ${ }^{39}$, de Zach Blas, que te vuelven incomprensible ante el algoritmo de reconocimiento facial de plataformas como Facebook.

En resumen, el campo de la vigilancia supone un contexto interesante desde el punto de vista del media-flâneur, pues la vigilancia se aloja en la base del discurso sobre la migración y la seguridad, tan arraigado en Occidente.

\subsection{LA EXPLORACIÓN DE LO INVISIBLE}

Esta tercera propuesta tiene que ver con la manera en la que se visibiliza o invisibiliza el mundo a través de las tecnologías digitales. En los años 20 algunos surrealistas experimentaron con la idea de la flânerie alejada de las metrópolis, basada en la deriva campo a través como medida de explorar el vacío «como si la intención de superar lo real mediante lo onírico estuviese acompañada por una voluntad de retorno a unos espacios vastos y deshabitados, en los límites del espacio real $\aleph^{40}$. Esta metodología, aunque fue criticada duramente por los situacionistas al «no haber llevado hasta sus últimas consecuencias las potencialidades del proyecto dadaísta » ${ }^{41}$, promueve explorar la periferia de los centros de poder y representatividad, allí donde reside la verdad y hacia donde la autora Remedios Zafra fija la atención: «Es lo que no puede ser visto lo que se nos posiciona como deseo, a veces desde la curiosidad, y otras desde la necesidad ${ }^{42}$.

Desde las plataformas de mapas hasta los buscadores de Internet, la exploración del mundo y todo lo que contiene está basada en una óptica computacional, que muestra esas imágenes terrestres en base a su relevancia mediática. Los resultados de búsqueda, ya sea en los buscadores, en los vídeos que recomienda Youtube o los marcadores inscritos en el mapa de Google Earth, dan forma al mismo mapamundi occidental.

Los antiguos cartógrafos griegos usaban dos categorías: la ecúmene hacía alusión a las áreas conocidas del mapa, entendidas como habitadas (y controladas), mientras que la anecúmene hacía referencia a las áreas desconocidas o deshabitadas. En el mapamundi que nos ofrecen los grandes medios digitales la ecúmene se concentra en los centros de poder. Por tomar un ejemplo podemos fijarnos en las representaciones de Google Maps. Los centros de poder son, en definitiva, las áreas que concentran mayor influencia mediática, es decir, las ciudades. En estas áreas el mapa se sobrecarga de marcadores y de fotografías, también tiene mayores referencias y menor margen de error a la hora de usar la navegación GPS. Incluso las ciudades gozan de una representación tridimensional que hasta parece convertirlas

39 Zach Blas, «Facial weaponization suite», web personal, https://zachblas.info/works/facialweaponization-suite/ (consultado el 31 de agosto de 2021).

${ }^{40}$ Careri, op. cit., 82.

41 Ibidem, 90.

${ }^{42}$ Zafra, op. cit., 57. 
en un videojuego donde las podemos sobrevolar para distinguir las formas de sus edificios, terreno y árboles.

Sin embargo, para llegar a reconocer el mundo que es mirado bajo la óptica computacional, no es adecuado atender a los epicentros de visibilidad. Por el contrario, para llevar a cabo un estudio más preciso del mapa del poder, es necesario fijar la mirada en el anecúmene. Es decir, atender las áreas deshabitadas, pobres en representación por parte de Google y su mapamundi, para discernir qué es lo que el régimen visual occidental no cree interesante mostrar. Es en la periferia donde se ubican los elementos que dan soporte a la metrópolis. No es casualidad que el mapamundi del imperio sobrerrepresente los territorios que domina, mientras que da la menor cantidad de detalle posible de los territorios de conflicto. En el imaginario de Google Earth, al impresionante modelado 3D de la ciudad de Nueva York y cada uno de sus edificios, se antepone una Kabul bidimensional: una mera textura que cubre la leve tridimensionalidad del terreno sobre el que se levanta realmente la ciudad, obtenido mediante escaneado topográfico desde satélites. En un lado del mapamundi, las ciudades del imperio se representan esplendorosas, erigidas en una materia 3D digital a la que Occidente aspira convertirse; en otro lado, los centros de producción del capital, siempre en estado de conflicto, quedan representados como ruinas. Remiten a esos yacimientos arqueológicos donde de los vecindarios sólo queda el trazado de los cimientos. Y de una manera asombrosamente similar, ante un impresionante modelado de la ciudad de Madrid, los pueblos de Cuenca, Soria o Teruel (en definitiva, todas las provincias rurales) son ruinas derribadas sobre un terreno escaneado.

En alusión a estos planteamientos están los proyectos artísticos que tratan de explorar esos límites de la representación, así como la mirada a las fronteras geográficas que evidencian la existencia de todo un mundo más allá de estos límites. En este argumentario puede ubicarse otro trabajo de Azahara Cerezo: Principios de trazabilidad (2017), un intento de traspasar la frontera a través del medio digital hacia ese anecúmene, que "consiste en el envío de frames del film Sans soleil (1983) a direcciones IP de la red que conecta con Tindouf (Argelia), región de campos de refugiados saharauis» ${ }^{43}$.

También, desde un punto de vista muy diferente, se podría plantear el proyecto moc.elgooG $(2012)^{44}$, de Heather Dewey-Harborg. Este trabajo consiste en una copia del buscador de Google que ofrece una versión invertida de la pantalla de resultados de búsqueda. Es decir, presenta en primer lugar las últimas entradas, aquellas a las que es muy difícil llegar y acaban condenadas a la desaparición.

43 Azahara Cerezo, «Principios de trazabilidad», Web personal, http://www.azaharacerezo. com/principios-trazabilidad.html.

${ }^{44}$ Heather Dewey-Harborg, «moc.elgooG», Web personal, https://www.deweyhagborg. com/projects/moc-elgoog. 


\section{CONCLUSIONES}

En definitiva, la media-flânerie puede entenderse como una actualización de las prácticas tradicionales, teniendo en cuenta que el mundo metropolitano que antaño recorría el flâneur está hoy atravesado por su propia representabilidad en los medios digitales. No obstante, hay muchos aspectos de sus referentes originales que el media-flâneur sigue manteniendo, de los que rescataríamos aquellos que tienen que ver con la relación del individuo con el panorama de control y omnipresencia presente en la sociedad digital. En este sentido, es necesario seguir produciendo discursos en torno a la telepresencia, que nos permite ver y actuar en lugares remotos a tiempo real sin peligro para nuestro organismo, y de un mismo modo reflexionar acerca de las consecuencias de la velocidad de transmisión de datos.

También hemos mostrado cómo las experiencias del recorrido están, dentro del marco de la mediación digital, estrechamente relacionadas con la sociedad de consumo: los viajes, los videojuegos, la realidad virtual, el imaginario de redes sociales, etc., son ejemplos de esta implantación de monetización del tiempo libre e, incluso, gamificación de la experiencia (término que explica cómo el consumo y el trabajo han adoptado metodologías propias del videojuego basadas en el análisis de datos masivos). Todo este panorama tiene una infraestructura de escala mundial tanto física como geopolítica que es necesario tener en cuenta, y que el mediaflâneur tiene que explorar.

Por otra parte, las posibilidades técnicas y discursivas que nos ofrecen los medios digitales propician hoy el crecimiento de una enorme comunidad creadora que ya no está supeditada exclusivamente al arte. La media-flânerie invita a ser practicada desde otras disciplinas como el activismo, la divulgación, el entretenimiento, la informática y otras ramas técnicas y científicas... En el caso de esta investigación, muchas de las orientaciones ideológicas de la media-flânerie están basadas en la ética hacker, un código transversal que a menudo ha reunido en un mismo lugar a artistas, hackers, makers, investigadores de innovación social y toda una comunidad de pensamiento basada en las aplicaciones socioculturales de la técnica digital.

Todavía no queda concretada una definición de lo que significa realmente ser media-flâneur. Esa tarea le corresponde a la comunidad, que irá completando, complementando, erigiendo, derribando y transformando el término mediante su hacer. Por tanto, es bueno insistir en que la catalogación de los referentes reunidos en este artículo podría haber sido distinta desde el bagaje de cada cual. De hecho, es muy posible que la mayoría de artistas no se haya planteado la media-flânerie como estrategia o temática. Incluso muchos no aplicarían el término a su obra en absoluto. Sin embargo, se anima a quien lea esto a reflexionar en su definición, a sacar sus propias conclusiones y a ponerlas en práctica en sus próximos trabajos.

Que este sea el primer paso de un viaje al infinito. 


\section{REFERENCIAS}

Alcaide, María. «My terrorist lover». Web personal. https://mariaalcaide.com/work/my-terroristlover/, (consultado el 31 de agosto de 2021).

Arias, Rubén Ángel. «METRÓPOLIS. Jon Gorospe». Centro Cultural Montehermoso. https://montehermoso.net/pagina.php?id_p=2293, (consultado el 31 de agosto de 2021).

Arregui, Manu. «Ejercicios de medición sobre el movimiento amanerado del cuerpo». Web personal. https://manuarregui.com/portfolio/ejercicios-de-medicion-sobre-el-movimiento-amanerado-del-cuerpo-2017/, (consultado el 31 de agosto de 2021).

BALAC, Marion. «Anonymous Gods». Web personal. http://www.marionbalac.com/works/anonymous-gods/, (consultado el 31 de agosto de 2021).

BALAC, Marion. «Les Enfants de Val d'Europe». Web personal. http://www.marionbalac.com/works/ les-enfants-de-val-deurope/, (consultado el 31 de agosto de 2021).

Bartholl, Aram. «Map». Web personal. https://arambartholl.com/map/, (consultado el 31 de agosto de 2021).

Baudrillard, Jean. Cultura y simulacro. Barcelona: Kairós, 1978.

Bazdyrieva, Asia, Solveig Suess, y Jessika Khazrik. "Geocinema». Web del proyecto. https:/geocinema.network/, (consultado el 30-8-2021).

Benjamin, Walter y Rolf Tiedemann (ed.). El París de Baudelaire. Buenos Aires: Eterna Cadencia, 2012

Bey, Hakim. T.A.Z. Zona Temporalmente Autónoma. Madrid: Enclave de Libros, 2014.

BLAs, Zach. «Facial weaponization suite». Web personal. https://zachblas.info/works/facial-weaponization-suite/, (consultado el 31 de agosto de 2021).

Blisset, Luther, Sonja Brünzels y Grupo autónomo AFRIKA. Manual de guerrilla de la comunicación. Barcelona: Virus, 2006.

Bratton, Benjamin. The stack: On software and sovereignty. Cambridge (MA): MIT Press, 2015.

CAReri, Francesco. Walkscapes: El andar como práctica estética. Barcelona: Gustavo Gili, 2014.

Cerezo, Azahara. «Paisajes digitales de una guerra». Web personal. http://www.azaharacerezo.com/ paisajes.html, (consultado el 31 de agosto de 2021).

Cerezo, Azahara. «Principios de trazabilidad». Web personal. http://azaharacerezo.com/principiostrazabilidad.html, (consultado el 31 de agosto de 2021).

CRISPIN, Sterling. «Data masks». Web personal. http://sterlingcrispin.com/data-masks.html, (consultado el 31 de agosto de 2021).

Cruz, Pedro y Lidia García. 2019. "Cuerpo, máscara y biopolítica. Estrategias de opacidad en la era del big data». ASRI. Arte y Sociedad. Revista de Humanidades digitales 17 (2019). https:// www.eumed.net/rev/asri/17/panoptico-digital.html, (consultado el 31 de agosto de 2021).

Dewey-Harborg, Heather. «moc.elgooG». Web personal. https:/www.deweyhagborg.com/projects/ moc-elgoog, (consultado el 31 de agosto de 2021).

Harvey, Adam. «CVDazzle». Web del proyecto. https://cvdazzle.com/, (consultado el 31 de agosto de 2021). 
Hoffmann, E.T.A. «La ventana esquinera de mi primo». El espejo gótico. http://elespejogotico. blogspot.com/2009/11/la-ventana-esquinera-eta-hoffmann.html, (consultado el 31 de agosto de 2021).

LAND, Marco. «Digital Detox». Web del proyecto. https://digitaldetox.marco.land/, (consultado el 31 de agosto de 2021).

Lovink, Geert. Tristes por diseño. Las redes sociales como ideología. Bilbao: Consonni, 2019.

Malo, Eduardo. «Assasins's Creed ayudará en la reconstrucción de Notre Dame». MuyComputer. https://www.muycomputer.com/2019/04/17/assasins-creed-reconstruccion-notre-dame/, (consultado el 31 de agosto de 2021).

Manovich, Lev. El lenguaje de los nuevos medios de comunicación: La imagen en la era digital. Barcelona: Paidós, 2006.

Martínez Garrido, Pablo. «Dudar del algoritmo». En Inmersiones 12. El arte del futuro, el futuro del arte, 8. Vitoria-Gasteiz, 2019.

Martínez Garrido, Pablo. «Proyectos artísticos». Non Player Character. https://nonplayercharacter.home.blog/category/proyectos-artisticos/, (consultado el 31 de agosto de 2021).

Presner, Todd. «Digital Geographies: Berlin in the Ages of New Media». Spatial Turns 75 (2010). https://doi.org/10.1163/9789042030022_023, (consultado el 31 de agosto de 2021).

Santamaría, Mario. «The non-imaginary museum». Righted-museum, https://righted-museum. tumblr.com/, (consultado el 31 de agosto de 2021).

Surveillance Camera Players. Web del colectivo, http://www.notbored.org/the-scp.html, (consultado el 31 de agosto de 2021).

The Institute for Applied Autonomy. «iSee». Vimeo, https://vimeo.com/6163268, (consultado el 31 de agosto de 2021).

Vavarella, Emilio. 2013.Some personal thoughts on Google mapping. Web personal del autor. https://emiliovavarella.com/archive/google-trilogy/report-a-problem/, (consultado el 31 de agosto de 2021).

VIrILIO, Paul. 1992. «Big Optics». On Justifying the Hypothetical Nature of Art and the Non-Identicality within the Object World. En Archive of Digital Art, editado por Peter Weibel. 1992.

Zafra, Remedios. Ojos y capital. Bilbao: Consonni, 2015. 